\title{
(Infinite) Absolute Negativity: The Brief Epics
}

\begin{abstract}
$\mathrm{T}$
o approach Blake's corpus in terms of sectors is to displace any genetic narrative (either of evolution or repression) that one might construct because the texts follow each other chronologically. Each sector provides a perspective on the whole that inscribes rather than anticipates or surpasses the intentions of other sectors. Thus, the earliest texts encourage us to experiment with the priority of individual experience over systematic constructs. In so doing, they open canonical reading to problems of cultural difference. In the brief epics, which more assertively begin the construction of a canon, we are encouraged to play with the absorption of difference into identity through the subsumption of present into future. But here, too, the traditional hermeneutic promoted by the later prophecies encounters metaphysical if not cultural challenges. If Blake's work differs from earlier canons, it is in the fact that his canon is not a preestablished structure but something that he must create through evidence and consensus. The texts we shall consider here are paradigms for the way the supplementary use of hermeneutics in forming canonical values necessarily stimulates a certain reflexiveness toward that project.

The brief epics differ from the previous texts in their renunciation of an individual perspective in favor of an omniscient voice that tries to see events both transcendentally and historically. Attempting to construct a phenomenology of history, Blake sometimes brings present, past, and future together in one text like The Marriage. But more often he deals with them separately, in a concession that history cannot yet be put together. These texts, however, are quite different from the final prophecies. They lay the groundwork for a canon by implying their own con-
\end{abstract}


tinuation in some further text and by thus making the part a sign of some absent whole. But it is not until later that Blake introduces the strategies typical of canon formation: the exclusion of certain perspectives and the incorporation of others as partial types of truth. Moreover, the early poems are prophetic in wanting to move toward the future, but this movement is hortatory rather than predictive because voice and event are not fused. If Milton is more grounded in a personal narrative, that is because Blake has withdrawn from the theater of history to what (superficially at least) seems the more tractable stage of the self. The early prophecies situate themselves in a historical world, that of Europe in the late eighteenth century, and the abstraction of prophecy from event or of voice from subjectivity is a concession to the unreadability, perhaps the unmanageability, of history. Not only is the realization of the vision adumbrated in The Marriage deferred, its central principles are also challenged: principles such as the attribution of the fall to Urizen and to his imposition of boundaries, our power to repeal the chaos we have created, and indeed the very possibility of organized innocence. The insecurity of the secular scripture confirmed through canonical reading is reflected in Blake's continued use of mobile forms that make 'omniscience' no more than a perspective. Thus, at the beginning of Urizen Blake assumes the stance of the Eternals, only to withdraw them from the action. The Eternals thus emerge as an intent at transcendence that Blake can do no more than inscribe in the text.

\section{Europe: A Prophecy}

Our discussion will focus on Europe and Urizen, so as to bring out how they stimulate and displace the negative hermeneutic necessary to fit them into Blake's canon. The text of Europe is assembled out of several pieces: the narrative itself, a preludium, a title page, a design of a Urizenic figure mapping the world with compasses, and a preface that exists in only two copies. Superficially we may be reminded of Jerusalem, where each chapter is similarly introduced by a combination of a preface and either a lyric or motto. But the later poem's preface draws the reader into a space of authority, by characterizing the author we must accept or reject. By contrast, the prefatory materials to Europe are like a series of asymmetrical frames from which 'Blake' seems teasingly absent. When he does represent himself, as the one who hears the fairy's song in the preface, it is in a whimsical way that mocks our attempts to grasp him. The text gives us its meaning as something that must be pieced together but breaks and interchanges the frames that we might otherwise use to give it its bounding outline. Its construction raises at the 
outset the question of interpretation, forcing us to encounter problems of structure before we hear the 'voice' promised by prophecy, and thus suspending rhetoric and the powerful responses it arouses in epistemology.

The simplest of the frames are the frontispiece and the title page. The picture of the Ancient of Days, first in all but one copy, suggests that we are entering a world of restriction. The title page with its description of Europe as a 'prophecy' allows us to think of that situation as open to change, a statement that things will change or that they should change. In different proofs of the title page, moreover, the figure caught in the coils of the serpent is Urizen or Los. ${ }^{1}$ We thus enter the narrative at a threshold between the actual and the possible. The narrative itself telescopes all of Christian history into a few pages before precipitating itself toward a climax of indeterminate import:

Then Los arose his head he reard in snaky thunders clad: And with a cry that shook all nature to the utmost pole, Call'd all his sons to the strife of blood.

$(\mathrm{E} 66 ; 15: 9-11)$

To follow Erdman in interpreting the 'strife of blood' as a reference to England's counterrevolutionary war against France is to read the poem as a corrective satire. ${ }^{2}$ To see the climax as representing the revolution itself is more pessimistic, for it is not just Orc but also Los (clad in snaky thunders that recall the serpent temple of Baconian science) who is now internally bound in a cyclic entwinement with what he opposes. On the referent of this phrase, deliberately obscured like the word 'prophecy' on some copies of the title page, depends our sense of how 'Blake' reads cultural history. That the poem encourages us to reflect on how we construct a hermeneutics of history is evident in the way it interrupts its mythopoeic style with neo-Hogarthian designs such as plate 7 . These designs make myth responsible to a world of historical detail and encourage us to apply it to specific events in the way that Erdman does. On the other hand, the discontinuity between realistic and visionary segments makes us wonder whether myth can be used to read history: whether it does not encounter an obscurity about which part of the pattern relates to which event.

At the root of our uncertainty about whether a negative hermeneutic can be used to bridge the gap between myth and actuality is the gro-

${ }^{1}$ David V. Erdman, The Illuminated Blake (London: Oxford University Press, 1974), pp. 396-97.

2David Erdman, Blake: Prophet against Empire (1954; rev. ed. Garden City, N.Y.: Doubleday, 1969), p. 264 . 
tesquely parodic mode of the narrative-not something we find in the original scriptures. Echoing Milton's "Nativity Ode" but making the 'secret child' Orc instead of Christ, the text turns Miltonic Christianity into a cinematic horror show whose overblown figures explode it from within. Parody obviously does not posit in any conventional sense, but whether it posits by negation and thus yields to hermeneutic reading is what remains ambiguous. Richard Poirier distinguishes between a parody that is "other-directed-by one writer against another or at the literary modes of a particular period," and a much more recent literature of selfparody that "shapes itself around its own dissolvents [and] calls into question . . . the activity itself of creating any literary form." ${ }^{3}$ Blake himself seems to be writing both kinds of parody, for if the prophecy satirizes Milton so as to make us reverse the catastrophe he has produced, it also bitterly mocks The Song of Los with its celebration of Orc so as to consume what it posits through negation. Moreover, it is unclear whether we can even make Poirier's distinction. Parody is fundamentally imitation: whether one sees the imitation as cathartic satire or as obsessive repetition, there is some kind of identification between the parodic text and what it projects as other. While reducing what it mocks to a series of empty forms, the parody itself remains locked in the same hollowness, a mockery of itself. Thus we often wonder whether figures like Orc and Los provide alternatives to Urizen or simply replicate the structure of what is already a parody. At the same time parody, however selfconsuming, cannot but retain the trace of a belief in truth and origins precisely because it is a form of imitation, although an iconoclastic one. Parody mimes an ideology that has been reduced to a formalism. Thereby constituting itself as a reflection of a reflection, it also creates by the very act of imitation the expectation of a positive source travestied by the sources it discovers. That Blake conflates in the figure of Orc elements of Satan and Christ is a thematic symptom of the ontological structure of parody as a mode in which negation is not nonbeing but the ground of coming-to-be. For the nativity evokes as an empty schema a pattern that neither Orc nor Christ fulfils, and that pattern then becomes a shadow that futurity casts upon the present, unsettling any identification of the text as a prophecy of doom. To put it differently, parody does not posit anything. But linked with prophecy, it may have the hermeneutic structure of what Kierkegaard calls infinite absolute negativity. Even as it negates everything, it may ask the reader to imagine that it does so from the standpoint of a truth that it does not yet embody.

Our first reading of the narrative is by way of the preludium, which in most copies is unaccompanied by any further preface, and which thus 
seems to frame the rest of the poem in the voice of the nameless shadowy female. Reading it mimetically, we might see the prophetic bitterness of the text as unable to do more than reinscribe things as they are. The "nameless shadowy female" is a will that has not yet achieved representation. She first pictures herself as an inverted flower whose roots are "brandish'd in the heavens" and whose fruits are buried in the earth (E6o; 1:8-9), recalling bitterly those flowers in Thel and Visions which believed that being uprooted by experience could be joyful. Wrapping herself in a "turban of thick clouds" and a mantle of "sheety waters" (E61; 1:12-13), she seems a figure similar to the Earth of Experience. Like Earth, she sees her potential as stifled and sees life as an endless cycle in which revolutionary energy bursts forth only to be stamped with Enitharmon's "signet" in the "solid form" of things as they are (E61; $2: 7-10$ ). Her lament provides a preview of the narrative that follows and also, since she may be Blake's muse, a commentary on the poem's mode: warped and inverted, turbaned in an imperious obscurity that folds inward to an inner void, a "secret place" (E61; 2:18). To see the prophecy from the perspective of the shadowy female is to accept its parodic inversions as self-consuming rather than apocalyptic, and to deconstruct the negative hermeneutic that parody seemingly offers. Fundamentally obscure, the prophetic voice acknowledges its failure at representation in the concluding image of secrecy and involution:

\section{... I roll inward \& my voice is past.}

She ceast \& rolld her shady clouds

Into the secret place.

$(\mathrm{E} 61 ; 2: 16-18)$

But even without the preface there are indications that a purely deconstructive reading is limited. For one thing, the shadowy female addresses herself to someone who might think differently from her. She poses self-justifying questions, asking why she should hope, given her experience so far. She asks, "who shall bind the infinite with an eternal band," thus constructing her statement of the paradox that necessarily consumes the infinite over the recognition that there may be bands that do not bind $(\mathrm{E} 61 ; 2: 13)$. Addressing herself nominally to Enitharmon but also to some other voice that reproaches her for her premature despair, she tacitly raises the possibility of reading the text of history differently. Like "Earth's Answer," the voice of the preludium is unsettled by its dialogical emergence in relation to a more hopeful voice that it can neither accept nor totally ignore. Moreover, the gender of the shadowy voice is significant. For in responding to it as specifically female, we become aware that oppression and helplessness are not archetypal real- 
ities, as her mythic language would have us believe, but aspects of the way women are figured and socialized. We see that the female's predicament is not preordained, and that she is a historical construction that then constructs history in a certain way. To introduce the supplement of gender is not, however, to produce a hermeneutic transfiguration of the text, since gender (like history itself) is a reflexive category. Thus, we may also recognize that what we would substitute for the female's construction of history, namely, the image of a transcendental subject able to cast off its mind-forged manacles, is equally a figure. As such, it may be unresponsive to woman's experience of being helpless, as well as to the self-doubt implicit in Blake's engendering of the prophetic voice as female.

As important as gender to the marking of limits is Blake's segmental construction of the poem. Segmentation functions somewhat like aphorism in creating spaces between texts that act as frames which "magnify the power of exaggeration within them but don't allow it to penetrate beyond their confines." 4 In other words, the preludium is stopped from functioning as the major premise in the poem's argument because its voice is placed outside the text of the prophecy. To absorb this voice into the subsequent text would be to naturalize it - a move that Blake arrests by conspicuously isolating it from the rest of the narrative. He also 'ungrounds' it, for it seems to come from nowhere, to hover abstractly like a state that we may pass through, but not to have the identity of a person whose origins we know. While the voice has interiority and thus pathos, we are displaced from an affective identification with it by the fact that it has no exteriority. It is almost impossible to visualize this shadowy female who is first an uprooted plant and then (dis)appears in a turban of clouds, who seems to originate from "out the breast of Orc" but who then brings forth from her bosom the "howling terrors" and "myriads of flames" that earlier seem to have produced her (E6o-61; $1: 1,2: 4,9)$. The paradoxical genetic relationship between Orc and the female creates a radical uncertainty as to the identity of this shadow who is known to us only as a sequence of stylized responses (deracination, turning inward, secrecy). Is her despair the inevitable consequence of Orc's destructive revolutions, or does her despair produce revolution in such a way that it must be destructive? What, moreover, is her relation to Enitharmon? She addresses her as though she were the victim of Enitharmon's machinations, as "mother Enitharmon" and thus as the origin of her woes $(\mathrm{E} 60 ; 1: 4)$. Yet her own role as mother of the howling terrors, which is another name for Orc, parallels Enitharmon's role as

\footnotetext{
${ }^{4}$ Alexander Nehamas, Nietzsche: Life as Literature (Cambridge, Mass.: Harvard University Press, 1985), p. 23.
} 
mother of Orc and raises the possibility that the shadowy female and her mother are aspects of each other. The relationship between these characters who intergenerate each other takes form in what Ault calls a "causal loop," a "perspective transformation" in which temporal relationships are constantly transposed, such that something that precedes an event suddenly comes into being only as a result of the event it precedes. ${ }^{5}$ Such loops bring to the surface of the text an undecidability that can sometimes create openings. In this case the loop makes us aware of the narrative as a transformational surface that keeps generating voices and characters to explain itself, freeing us in the process from the demonically cyclic explanation of history to which the shadowy female ascribes the involution of prophecy. In other words, it makes us aware that the narrative field of this poem is highly fluid, and that the perspective from which we structure it is capable of changing.

Nevertheless, if the preludium de-identifies us from its voice and thus from a fatalistic reading of the prophecy, it does not really give us another position with which we can identify, producing hope only negatively as a disembodied space inside despair. What radically alters the poem is the addition of the preface in copies $\mathrm{H}$ and $\mathrm{K}$. Here Blake overhears the song of a fairy sitting on a streaked tulip, carries him home while gathering flowers on the way, and sets him down on his parlor table, where the fairy dictates Europe. This whimsical attempt to displace the shadowy female as the origin of the narrative begins with an account of expanded perception:

Five windows light the cavern'd Man; thro' one he breathes the air; Thro' one, hears music of the spheres; thro' one, the eternal vine Flourishes, that he may receive the grapes; thro' one can look. And see small portions of the eternal world that ever groweth; Thro' one, himself pass out what time he please, but he will not.

(E6o; iii:1-5)

We are sufficiently familiar with passages that speak of seeing eternity in a grain of sand to assume that this must finally be the voice of Blake. Thus, Leslie Tannenbaum links the fairy to the fairies and giants in the preface to Jerusalem and argues that in substituting it for the traditional Christian muse Blake continues his parody of Milton through a countergenealogy of morals. He returns to the vision of the Ancient Poets in The Marriage who found "an immense world of delight" in the senses $\left(\mathrm{E}_{35} ; 7\right)$, and he dismisses as unnecessary the dualism of sense and spirit that produces Europe's woes. From the view that the poem has as its goal 
the "exposure of error," 6 there follows a view of the preface as enacting a hermeneutic program based on a reversal of perspective. Its stylistic incongruity is part of this reversal. To read the preface as a postscript, as we do knowing that it was added to the poem, is to move from a melodramatically serious vision to a charming anecdote that suddenly turns us upside down so as to make us wonder if we are not now seeing things the right side up. Granted that a fairy does not belong in a parlor. But are not Enitharmon and Ocalythron equally preposterous (and much more harmful) concoctions? Treading a fine line between the absurd and the miraculous, the fairy asks us to see the narrative as a nightmarish fiction. For a moment he seems to be parodying Europe only to appear as absurd himself, but then he puts us through a further reversal of perspectives by juxtaposing pastoral and humor, Albion's fairies and eighteenth-century domestic interiors, in such a way as to open inside the ridiculous a window into the miraculous. As a hermeneutic signpost, what this poem tells us is to turn Europe around and around till the chinks in its cavern become windows into eternity. The cavernous form of parody, which sometimes seems to consist only of the void created by hollowing out the object of the parody, must be read in such a way. Parody in the bitter form it takes in the narrative carries us to the vortex of vision. To pass through this vortex is to revision the parodic process in another more creative form.

What the preface generates, in other words, is a dialectically intricate hermeneutics of reversal. The seeing of the vortex (as opposed to the vortex itself) is Blake's image in Milton for a hermeneutic that grasps 'reality' as a transformational surface. As the mental traveler enters the vortex, it contracts to a point of nonentity. As he emerges from it, he sees it in reverse, expanding behind him:

The nature of infinity is this: That every thing has its Own Vortex; and when once a traveller thro Eternity. Has passed that Vortex, he percieves it roll backward behind His path, into a globe itself infolding; like a sun:

Or like a moon, or like a universe of starry majesty.

$\left(\mathrm{E}_{109} ; 15: 21-25\right)$

In the passage immediately following this one, Milton, having entered his shadow, the body of beliefs he can no longer inhabit, enters the inert Albion, and his vision contracts toward imaginative death. At the same time, the Eternals, from the other end of the narrative vortex, see Milton's "immortal Self" sleeping "on a couch / Of gold" (E109; 15:11-13).

${ }^{6}$ Leslie Tannenbaum, Biblical Tradition in Blake's Prophecies: The Great Code of Art (Princeton, N.J.: Princeton University Press, 1982), pp. 181-82. 
As a figure of reading, the vortex provides a means of containing the proliferating reversals of parody. As we travel through Europe, the parody first generates a contracting vortex, inverting the "Nativity Ode" so as to empty Milton's corpus of life. It mocks Milton into nonentity but also restricts imaginative space so that we think of nothing except the horrors of eighteen hundred years of history. As parody takes a more open form in the preface, the fairy's song allows us to emerge from the vortex. The narrative of Europe is still the vortex we are about to enter. But we also know that when we return to the text's beginning, we can see the vortex roll backward behind us and can see the parody of Milton not as an inwardly spiraling despair but as "a globe itself infolding": a new world, though still limited and involuted.

It is clear that the preface expands the ways we can perceive the narrative by effecting a somersault from parody to vision. But we also cannot ignore the ambiguities of its style and placement. For its modular status and incongruous style suspend its ability to function as the major premise in a (re)visionary argument. Recalling the introduction to Innocence, where the piper is inspired by a child on a cloud, this poem almost seems to parody an equation of it with the earlier one by inspiring a narrative radically discontinuous with its fairy-tale world. The fairy is oddly indifferent to the content of what he dictates, as he sits in a parlor sheltered from the international warfare described in the poem. Instead, he laughs aloud to see the flowers "whimper because they were pluck'd" (E6o; iii:19-21). The parlor itself is a somewhat odd place for the fairy to be. The paradoxical urban fairy is of course a parody of precisely the response sketched here. But on another level the disjunction between the preface and the narrative reminds us of a later poem: Keats's Lamia, where the charming story of Hermes and the nymph tells us how it is in eternity, but evaporates into anachronism as we confront the tangled world of Lycius and Lamia.

Moreover, the preface is simply not present in most copies, as if this way of seeing is not feasible most of the time. Placed before the title page and the picture of the Ancient of Days in one copy, it is placed after these plates and before the lament of the shadowy female in the other copy. What this means is unclear, except that we should not too easily settle into one view of the perspectival relationship between the preface and other segments. Perhaps by placing the segment inside the Urizenic frame, the text suggests that it is fantasy to emancipate the fairy from the laws of space and time. Or perhaps it suggests that inside this Urizenic world there is a window that looks outside it. Placing the segment outside the Urizenic frame has no positive meaning either, except as a decision not to place it inside, which itself can be viewed from more than one perspective. Depending on how we see the inner placement of the pref- 
ace, its placement outside may exempt it from the Urizenic world or may simply make it irrelevant to that world.

\section{The (First) Book of Urizen}

Lacking anything like the fairy's preface, The (First) Book of Urizen stimulates no visionary somersaults, so that the counterreading of things as they are occurs only negatively, as in the case of Europe's preludium. But if the text thereby exemplifies the tendency of a negative hermeneutics to collapse in on itself, it is also an instance of how negativity can have consequences that exceed the deconstructive. That the negativity of this poem is productive is due in large part to its intertextuality, Urizen himself being an intertextual figure whose refiguration elsewhere encourages us to re-vision this poem's deconstruction of itself. Urizen is Blake's most ambitious epic so far: an attempt to trace not simply the origins of European culture but of the (mis)creation itself. A first reading is depressingly bleak, unsettling any claim that the text forwards Blake's system by diagnosing the errors that have created the world of experience. The narrative begins after Urizen's 'separation' and depicts Eternity in a flashback that receives only four lines, as if the cosmos was never sufficient to have stood or free to fall. The Urizenic worldwhether it arises as an act of usurpation or as a natural mutationgenerates attempts at containing its disorganization which only replicate what they resist. The Eternals react to the chaos of experience by building a tent around the world $\left(\mathrm{E}_{7} 8 ; 19: 2-9\right)$. Los is more constructive, following the model of Christ and entering experience to save Urizen. But as he works at his forge binding Urizen, he, too, takes on the latter's functions, in Blake's first recognition that the imagination may be its own specter. Los then divides himself and fathers Orc, whom he nails to a rock in a curious disintegration of the Christian myth, which has 'Los' occupying the functions of both Christ and his destroyers. Because the plot of Urizen echoes but displaces the Christian story, the text seems to hollow out the positive model that it seeks to reinstall across its distortion.

Augmenting our sense of a text that deconstructs itself is the collapse of the oppositions that might make it the history of Urizen's 'error.' There is the erosion of the boundary between then and now which allows us to conceive of a world without Urizen. The Eternals claim that death enters the world af ter the separation of Urizen $\left(\mathrm{E}_{74} ; 6: 9-10\right)$. But according to Urizen, death exists in Eternity whose inhabitants already feel "unquenchable burnings" ( $\left.E_{71} ; 4: 13\right)$. The four-line description of Eternity is too vague and abstract for us to determine whether it is 
indeed a weightless freedom in which the senses can be expanded at will $\left(\mathrm{E}_{71} ; 3: 37-38\right)$ or, as Urizen claims, whether its fluidity is a chaos that requires the imposition of boundaries for its form to emerge. Clearly, what precedes Urizen's separation is inchoate, and it is only with the assertion of what Blake later called the 'selfhood' that the world we know emerges: the world of "beast, bird, fish, serpent \& element" (E70; 3:16). Because the creation is coeval with the fall, the fall cannot be a dereliction as it is for Milton, though what is created is a depressingly involuted form of life. If the text blurs the line between Eternity and Experience, thus disintegrating the norms from which Urizen has deviated, it also unsettles the opposition between Urizen and the unfallen Zoas on which Blake's later system is based. As positive models, the Eternals become constructs that the poem discards. As long as they simply are, they seem emancipated from the order of time and space. But as soon as they start to act, their affinity with Urizen emerges. They produce the seven deadly sins that are also attributed to Urizen $\left(\mathrm{E}_{72} ; 4: 49,5: 1-2\right.$, and $\left.4: 30\right)$. They stand "wide apart" from the earth in a posture of dualistic avoidance that mirrors Urizen's separation from the world of process $\left(\mathrm{E}_{73}\right.$; $5: 41)$. Significantly, their response to Urizen's separation is described in terms of a cloud rent by thunder: "Rent away with a terrible crash / Eternity roll'd wide apart" $\left(\mathrm{E}_{73} ; 5: 4-5\right)$. The image suggests that the fall is a violent, arbitrary event. But it also implies that the separation simply potentiates the disorganization of Eternity by disclosing what lies behind the mystifications in which we cloud it. This ambiguity about the chronology of Eternity and Experience is present from the very beginning: "Lo, a shadow of horror is risen / In Eternity!" (E7o; 3:1-2). The phrase "is risen" suggests an event, a cataclysmic change. But this change may not be from Eternity to the Urizenic world, for the shadow may be "in" Eternity itself.

Our sense that the Urizenic world could have been avoided is further unsettled by our uncertainty as to the chain of responsibility. From the outset, an indeterminate syntax casts doubt on our assumption that Urizen is the cause of what happens:

Of the primeval Priests assum'd power, When Eternals spurn'd back his religion; And gave him a place in the north, Obscure, shadowy, void, solitary.

$\left(\mathrm{E}_{70} ; 2: 1-4\right)$

Does he assume power in the sense of seizing it, or do we merely assume him to have power? The lack of an apostrophe in the word "Priests" (not "Priest's") leaves us uncertain whether the referent is singular or plural, 
and thus whether Urizen is the primeval priest or whether the Eternals are priests who assume the power to reject his religion, insensitive to the fact that "No man can think write or speak from his heart, but he must intend truth" (E1). We assume that it is Urizen who separates himself from the Eternals, but then he is also described as "rent from Eternity" $\left(\mathrm{E}_{74} ; 6: 8\right)$, as if by someone else, and he is characterized as "The obscure separation" (E73; $5: 40)$, as if he is simply an effect of an absent cause. In failing to explain how the fall occurred, the poem limits our ability to think of an origin that might have been different, leaving us simply with the fact of things as they are.

A second reading of Urizen would not begin with the text described here, but rather with its place in the secular scripture that Blake, by the time he engraved this poem, was trying to assemble. Such a reading would try to contain the deconstructive energies of Urizen and to find in the poem traces of its own later re-visioning. Constantly recalling Miltonic and biblical parallels so as to dispossess them of their positive potential, the text at first seems profoundly resistant to canonical strategies of recuperation. But in contrast to the bleakly naturalistic stories of Wordsworth's early phase, Blake's poem uses parody and grotesqueness to produce what Brecht calls an alienation-effect that prevents us from passively submitting to the plot. Parody allows us not to identify with Urizen, or not to see him as inevitable. We note how the cosmogonic decomposition that occurs as the text moves from Urizen to Los and Enitharmon to Orc is allegorized and thus dispossessed of psychic concreteness. Reason separates from the unified self, provoking imagination to bind it, but in such a way that imagination is divided by pity and produces revolution, which in turn is bound by imagination. This deeply troubling cultural deformation is then skeletalized, abstracted from our own experience, and mockingly represented through a succession of cellular fissions and incestuous births.

Dissociating us (however tenuously) from its world of distortion, parody frustrates the reader into constructing the absent norm against which distortion can be measured. Though it risks self-consumption, its instability can be appropriated by a hermeneutics of reversal that makes the negativity of the text into the ground of coming-to-be. For Blake would have found in Boehme and Paracelsus the ontology that generated Schelling's hermeneutic: an ontology in which opposites are mutually necessary and evil contains the root of good, thus generating the processes that lead to its own reversal. ${ }^{7}$ On one level parody remains caught in what Paulson calls an anal or regressive form of revolution,

\footnotetext{
${ }^{7}$ On Blake's reading of Paracelsus and Boehme see Erdman, Prophet against Empire, pp. 12,37 .
} 
while prophecy is more clearly progressive, an internalization of paternal authority. ${ }^{8}$ The revolt of parody is grotesque rather than sublime, a self-revulsion. But, on the other hand, the parodying of Milton-and (through Los) of Blake himself-could be said to cleanse and make available certain functions that can be used positively: the creative function misappropriated by Urizen, the redemptive function misused by Los, the function of exodus and liberation sketched in Fuzon. A traditionally hermeneutic reading would thus proceed by negating both the world of Milton's God parodied in Urizen, and the flawed figure of Los who is as far as Blake can get in conceiving a way out of the Urizenic system. Blake himself describes the positive thrust behind his strategy of negation in The Marriage, where he speaks of "printing in the infernal method, by corrosives, which in Hell are salutary and medicinal, melting apparent surfaces away, and displaying the infinite which was hid" (E39; 14). In an uncannily similar passage Kierkegaard focuses on the pedagogical reasons for using negativity:

there is a difference between writing on a blank sheet of paper and bringing to light by the application of a caustic fluid a text which is hidden under another text. Assuming then that a person is a victim of an illusion, . . if I do not begin by deceiving him, I must begin with direct communication. But direct communication presupposes that the receiver's ability to receive is undisturbed. But here such is not the case; . . . one must first of all use the caustic fluid. But this caustic means is negativity. (PV, p. 40)

A hermeneutics of negativity accounts for the most troubling aspect of the poem: the fact that the Eternals provide no viable alternative to Urizen. A reading of the poem as straightforward satire would have to construct a binary opposition between Urizen and the Eternals, in which they represent a truth from which he deviates, and in which his perversity is avoidable. As that opposition collapses, so, too, does the corrective authority of satire. Satire, at least in the form of stable irony, assumes a positive origin, but it is precisely that origin which Blake denies by making the creation and the fall simultaneous. Because positive norms have never existed, the poem can only negate. Allowing it to deconstruct both Urizen and the Eternals, a hermeneutics of negativity lets the text exist in a state of infinite absolute negativity without making its failure to conceptualize positive norms a renunciation of their possibility. This negativity, though potentially dialectical, is not like the positive dialectic generated by the Songs, where the innocence of the children is a shadowy type of something valuable. The Eternals have no positive value and are

8Ronald Paulson, Representations of Revolution $(1789-1820)$ (New Haven, Conn.: Yale University Press, 1983), p. 8. 
not models we can emulate: they arise only as a repudiation of Urizen, who also has no absolute value as something we can avoid, being shadowy and unseen. Potentiality can thus appear only as a gap within the negative and not in any positive way. The gap is sometimes innaccessible to language: it appears, for instance, in full-page designs depicting anguished figures who resist the world they have brought about. If the plot increasingly traps the characters in cycles of repetition, the "visions of dark torment" unfolded in the designs unsettle the "words," the consciously taken positions, that dictate each character's entrapment (E7o; $2: 6-7)$. Significantly, the preludium speaks both of "words" dictated to 'Blake' and of "visions" unfolded before him, describing the two media used in this text that is more dominated by full-page designs than any other in the oeuvre. The metaphor of dictation suggests a meaning already decided: one that is transmitted to Blake and petrified in the The Book of Urizen, in whose codification the Eternals as sources of Blake's inspiration are also accomplices. The concept of "visions" suggests something more immediate: a form of perception in which the signified does not precede its transcription, and in which what is seen is simultaneous with its seeing, as though things are still in process. Although the designs may not be any less pessimistic than the text, they are different in the mode of perception they generate in the reader. The text records what has happened; the designs involve us in what is still happening. Urizen, who lies in a "stony sleep" in the text $\left(\mathrm{E}_{74} ; 6: 7\right)$, is falling, weeping, struggling upward in the designs. Associating negativity with energy rather than petrification, the designs allow us to think of it as Boehme thinks of evil: as an intensifying anguish and darkness that ultimately develop a countermomentum strong enough to overcome their destructiveness. The designs stop the text and confront us with something that has not been said and can only be articulated in the cinematography of trauma. The form of their negation differs from that of the text, thus creating a gap within the text's negativity in which hope can produce from its own wreck the thing it contemplates.

As he developed his system, Blake created a context for his Bible of Hell that would enable readers to mobilize the negativity of texts like Urizen. But there are features unique to this text that may render such re-visioning problematic. For reading (whether hermeneutic or heuristic) occurs through levels of identification between us and the characters who represent us in the text, and through the speculative narratives that these relations of identity and difference allow us to construct. But it is not clear that the text contains 'characters' in the conventional sense. From the beginning it challenges its own personification of Urizen. It tells us that Urizen may simply be the name given to a mutation in the order of things: 
... what Demon

Hath form'd this abominable void

This soul-shudd'ring vacuum?-Some said "It is Urizen."

$\left(\mathrm{E}_{70} ; 3: 3-6\right)$

Because 'Los' and 'Urizen' are not so much personalities as functions, we increasingly notice the plot rather than its automated agents. It is as if the plot is a machine with its own logic: an empty logic in which actants are automatically transferred from function to function so as to abort the purpose of their previous function.

One of the more confusing aspects of the poem is the way it echoes and disorganizes the Christian story. Los recalls Adam whose wife is also wrenched out of his body; but he also plays the role of Christ as well as of Christ's destroyers. Hurled into his own region in the north where he divides and reproduces himself in a series of incestuous births, Urizen recalls Milton's Satan with his progeny, sin and death. But he also recalls God who creates the world in six days and rests on the seventh (E83; $25: 39-40$ ). It is not surprising that Urizen should conflate the functions of God and Satan in a poem meant to parody Milton. But then the Eternals also recall Milton's God, who stands wide apart from the fallen Adam, leaving Christ to save him. Dividing the characteristics of one biblical character between several actants in the Urizen story and then allowing one actant from the parodic version to transit several characters in the biblical story, the text seems to generate a narrative that is profoundly unreadable. Character names and plot functions do not stay associated long enough for us to place a character or know whether we should identify with him. This unsettling of the distinctions between characters is repeated at almost every level of the text, from its syntax to the organization of its parts. Thus Blake often uses dangling participles or ambiguously situated adjectives that can be referred to more than one character. An example is "Los wept . . . for in anguish, /Urizen was rent from his side" (E73-74; 6:2-4), where the word "anguish" applies to both Urizen and Los. A larger version of this phenomenon is the transposition of full-page designs to go with different parts of the text. Thus plate 27 , a picture of a figure fleeing with his back to us, comes between plates 23 and 24 in copies $C$ and G, but at the very end in copy A. Coming after the section on Urizen exploring his dens (or in the middle of this section in $\mathrm{B}, \mathrm{D}, \mathrm{E}$, and F), the plate seems to refer to Urizen. Coming at the end, it may also refer to Fuzon, whose exodus then becomes a turning away, a negative gesture that associates him with Urizen.

The reduction of personality to an effect of plot is further augmented 
by the displacement of characters in the narratological grammar of the poem. Urizen falls into a catatonic state after his speech in chapter II and appears only in genitive or passive constructions, until he briefly reemerges as the grammatical subject in chapter VIII, where he wanders through his dens in a manner that reminds us less of a tyrant than of the helpless voice of "London." Meanwhile Los, who plays the role of grammatical subject for five chapters (III-VII), simply disappears from the last two, as Urizen in the final chapter is once again transferred from the nominative to the genitive case. Characters do not seem to control events but to be produced, reproduced, and discarded by them. As the story opens, it invents Urizen so as to produce its own beginning. Failing thereby to recover an origin, it sets Urizen aside and invents Los as a way of moving toward its end. But 'Los' only allows the story to repeat itself, so he, too, is discarded, in favor of a Urizen who is again set aside because he no longer functions as villain. Finally, the text produces Fuzon, who is little more than a figure for an ending that might proceed beyond the middle. Less a character than a figure for a resolution or at least for change, Fuzon produces Blake's myth as a function of narrative desire.

The process by which the text (de)constructs characters to explain and complete itself renders cosmic history as a series of rifts and permutations profoundly resistant to humanistic reading. For the poem, rather like Byron's Cain, interweaves two very different genres. At times it is a cosmogonic narrative, an inquiry into origins that tries to understand the moral structure of the universe by creating a cast of characters who represent different aspects of the cultural mind. Profoundly hermeneutic in its desires, it casts itself in the mode of scripture so as to suggest that exegesis is possible. It inaugurates the romantic concern with myth as anthropology that culminates in Schelling's Philosophy of Mythology: a text concerned with myth as part of an ongoing hermeneutics of culture in which we create and interpret myths to understand and recreate ourselves. At other times the poem seems to be describing geological processes that have little to do with scripture. It reminds us of those deteriorationist accounts of the cosmos increasingly popular in romantic natural history, in which the decline of the cosmos has no discernible beginning or end. In contrast to Goethe's studies in biology, which led to the organicist and teleological models of narrative implicit in postKantian metaphysics, the model of time and thus of narrative that one might extrapolate from geological research is of a permutational system without a spiritual origin or telos, generating superfluous elements that are not integrated into the system. Goethe's model of structure led to a traditional hermeneutic able to grasp the inner form of a text. A model in which narrative is itself an effect of the text, in which writing unsuc- 
cessfully generates characters and episodes to explain its surpluses, calls into question the very notion of interpretation.

In other words, it is not just a question of deciding who is responsible for Experience, and whether the poem uses corrective parody to make us reorganize reality or existentially portrays a world from which there is no exit. There is ample evidence that Blake played with these alternatives and found them to be interimplicated. The many copies that omit plate 4 , in which Urizen explains his separation, support the first story by removing any inside view of his motivations and thus making his actions arbitrary. The copies that retain the plate create some sympathy for him and leave us wondering whether we would have done otherwise. On the other hand, the omission of plate 4 subverts the very story this omission supports, for it also removes the arrogant declaration of the law that explains the Eternals' rage. Proceeding directly from the disintegration of eternity at the beginning of chapter II to the rage of the Eternals halfway through chapter III, these copies make the Eternals' reaction seem excessive. We wonder who it is that blows the trumpet that ends Eternity. The text only tells us that "The sound of a trumpet the heavens / Awoke" (E71; 3:50-51). Plate 4, which then has Urizen speak, implies that he blows the trumpet as a prelude to the declaration of the ten commandments which rends Eternity apart. But the copies that omit plate 4 make it seem as if the Eternals, having just 'awoken' to the existence of Urizen, whose world precedes the description of Eternity in the order of the text and may thus coexist with it in the order of things, trumpet their rage and thus produce the cataclysms that formally end Eternity. In other words, these copies, by erasing the one segment in which Urizen acts and speaks, efface him as an origin of culpability. As in so many other texts where he changed the order of plates, Blake allows us to create more than one version of the story. But it is not just a question of deciding between these stories or even of combining them. For what they share is a humanistic assumption that events are created by people, and that interpretation tells and retells the story of those people. And it is precisely this anthropomorphism that is challenged by the text's grammatology.

To put it differently, the text borders on what de Man describes as 'unreadability.' This is not to say that the literal activity of reading is blocked, but that the poem seems to defeat any use of it as part of the self-understanding of the reader. The questions about interpretation raised by Urizen are thus more radical than anything we have encountered in Blake. For hitherto his emphasis on textuality has produced writings that can be interpreted in more than one way and has recognized how interpretation and culture intergenerate each other. Here, however, it is the very possibility of interpretation, and thus the value of 
the text as a cultural resource, that is called into question. Reading the whole through the part, we wonder whether this text does not suspend the entire project of Blake's canon. By absorbing mythmaking into a secular scripture, this project makes it part of cultural analysis and therapy. But perhaps there is no Los or Urizen, and perhaps the invention of stories is only a self-complicating deferral of the fact that reality cannot be constructed in anthropomorphic terms. Perhaps, on the other hand, the poem's unreadability is itself a perspective. My discussion of the text's displacements has deliberately ended in a thematics of genre to suggest that even its aporias, unlike those of rhetorical poststructuralism, are about something. They mobilize relationships between this and other texts, reinserting the text's very deconstruction of hermeneutics into cultural dilemmas about the limits of understanding that are still hermeneutic in form.

We can trace this intertextualization of the deconstructive to cultural tensions that may still be relevant today, and that construct deconstruction or its approximations diacritically in a larger field of possibilities. Scientific accounts of the cosmos that made human beings irrelevant were beginning to challenge the androcentric narratives of scripture. But the figures of scripture-figures like anthropomorphism, origin, telos-still had a powerful appeal and continued to intersect the very scientific accounts that challenged them. In Urizen itself the disfiguration of the characters by the text must be set against the enormous prominence given to the human figure-albeit grotesquely deformed-in the designs. These pictures force us to participate in the anguish of Experience and create a pressure to see beyond it. The radical disfiguration of hermeneutics that results from the language of Urizen may be simply one perspective that the poem asks us to consider. It is also clear that Urizen itself may be only one perspective in the intertextual dialogue of Blake's canon.

\section{Coda: Jerusalem and the Hermeneutics of Becoming}

The fact that Blake continued to engrave poems like Urizen and Europe alongside the final prophecies is evidence of his ongoing struggle with the specter of his earlier texts. Moreover, it allows us to read the final prophecies intertextually instead of according them the canonical privilege of what comes later. But it is also necessary to experiment with reading them autonomously, and as such Milton and Jerusalem mark Blake's abandonment of the heuristic text in favor of the 'work,' admittedly conceived as ongoing labor, yet tending nevertheless to reify process as a product in itself. Jerusalem consolidates the later Blake's commit- 
ment to a traditional hermeneutic, and in its discursive passages it provides exegetical principles for normalizing the earlier texts. Milton enacts a typological recuperation of the past that provides a paradigm for bringing Blake's Old Testament into the canon. Admittedly, these are not works of the kind Barthes designates as 'readerly.' Despite their assertiveness, they are not repositories of dogmas that we are supposed to consume passively. Instead, what they transmit to us is a semiotics of renovation: an activity that is more important than what Blake produces thereby. But the activity that the later prophecies model is radically different from the perceptual transactions stimulated by the early poems. It is, after all, the creation and not the interrogation of a system.

That Jerusalem functions primarily on a hermeneutic level rather than in terms of mimesis or reference, and that it can be read reflexively only if it is treated oppositionally, is what makes it a 'work' in the sense suggested above. Blake indicates the hermeneutic nature of his text in the preface and in the opening plates of chapter I, where he apologizes to the public for the "Enthusiasm of the following Poem" and hopes the "Reader will be with me, wholly One in Jesus our Lord . . . The Spirit of Jesus is continual forgiveness of Sin: he who waits to be righteous before he enters into the Saviours kingdom, the Divine Body; will never enter there" $\left(\mathrm{E}_{145} ; 3\right)$. Excusing the written text as imperfect, Blake asks us to treat it with charity and to recognize its status (in Coleridge's terms) as inspired if not revealed. The uncharitable division of the audience into "sheep" and "goats" that heads the plate is self-mocking only to the extent of conceding that there are imperfect readers as well as authors, and that they, too, deserve to be treated with patience. In the first few plates Blake pictures himself sitting at his desk, writing of the building of Golgonooza, which is not yet Jerusalem but its textual simulacrum, and struggling with the specter of his empiricism, which demands that vision be proved "by demonstration" and "not by faith" (E $147 ;$ I:4:28). Gradually 'Blake' is replaced by 'Los,' whose struggle with his specter is clearly repressive, but whose tyranny is put to us as necessary for imaginative freedom. It is the specter who works at the forge creating the poem, because it is the dark energies of "doubt \& despair" (E 153; I: 10:33) that must generate vision as a psychological supplement. That Blake represents despair as vital is suggested by the poem's opening image: "There is a Void, outside of Existence, which if entered into / Englobes itself \& becomes a Womb" (E144; I:1-2). Unless we enter into the void, nothing will be created. Once entered, the void becomes a contracted embryo with the potential to be a cosmos. Whether anything will be born from it is not clear from this image, which takes us only as far as the anguish of englobing and consolidating vision in the pain of conception.

By situating prophecy in the scene of its own writing, Blake introduces 
into the poem an awareness of textuality that is counteracted by the invitation to the reader to make the "types" that Blake prints out into truths through applicative reading. Vincent De Luca has persuasively described Jerusalem in terms of a textual sublime in which the reader is initially blocked by the visual appearance of the poem as a "wall of words," but then experiences a "countermovement of exaltation" in which he grasps the transcendental (in a Kantian rather than a Platonic sense). Relocating terms like 'gap' and 'abyss' in the vocabulary of the sublime, de Luca absorbs them into a hermeneutics of the sublime as opposed to a deconstruction of sublimation. Signs are passages to mental 'realities' that exist neither in the text nor in a realm of forms that it copies, but in the response elicited by the text. ${ }^{9}$ That the poem uses textuality in this way is undoubtedly true. But in addition, Jerusalem is part of a specifically romantic genre defined by Friedrich Schlegel when he speaks of a metawork that contains not only the text but also the story of its genesis and a self-commentary. Thus the poem begins with an account of why Blake must write it, which is then repeated more elaborately as an account of why Los must tame his specter; and at various points it produces metadiscursive summaries of what Blake thinks he is saying through his paraphernalia of characters and events. The text described by Schlegel is reflexive in ways that seem to verge on postmodernism but that actually have more to do with a hermeneutics of becoming. Situating itself in the author's life, it conveys the incompleteness of something that has not achieved the impersonality of classical art, and it suggests the urgency of its existential project. By interpreting itself, it conveys not self-mastery but a need for the supplement of reading. These attempts to understand itself are again symptoms of a lack of objectification, gestures toward a reader who will understand the text better than the author, given that the author already understands it better in the act of reflection than in the moment of conception. Schlegel, we must add, did not see the imperfection and involution of the romantic text as a flaw. Rather, he saw such texts as contextualizing themselves in an ongoing process, and asking that that process be continued in the reader.

Crucial to the deferral of meaning to the reader is the use of allegory. Allegory dissociates us from the characters and causes us to see them as 'representations.' That Blake uses an allegorical cast of characters is obviously puzzling, given his condemnation of the mode. One could note with Robert Gleckner that he distinguishes between "sublime alle-

${ }^{9}$ V. A. De Luca, "A Wall of Words: The Sublime as Text," in Hilton and Vogler, eds., Unnam'd Forms, pp. 218-41. 
gory" and allegory addrresed to the corporeal powers. ${ }^{10}$ Kant's theory of the sublime involves an initial dissociation of mind from matter, followed by an experience of (self)-identification in which the mind becomes lord and master. Transvaluing the physical into the metaphysical, sublime allegory would thus avoid the disembodied reification of vision in its physical covering, while using the dissociation of tenor and vehicle characteristic of allegory to make us see beyond the merely literal. In contrast to this metaphysical and visionary view of allegory, Steven Knapp associates sublimity and allegory in order to halt them at the dissociative stage. Foregrounding as it does the personification of figures as realities, allegory is a self-consciously rhetorical mode that risks reversibility: "Once the boundaries between literal and figurative agency were erased, it seemed that nothing would prevent imagination from metaphorizing literal agents as easily as it literalized metaphors." Moreover, allegory was connected in eighteenth-century usage with the sublime, which involved a simultaneous "dissociation from images of ideal power." To experience the sublime "was not quite, as some historians have argued, to identify oneself with a transcendent ideal of pure subjective power, but rather to entertain that ideal as an abstract, fantastic, unattainable possibility." 11 Knapp does not offer this as a description of Blake, who, along with Shelley, is a creator of myth rather than allegory. But even though Blake's allegory is mythopoeic, it seems that he uses the mode as a way of blocking identification with his characters and letting us perceive the 'states' they 'represent' on a screen of possibilities rather than in a world of identities. Los is, as it were, a mask for the reader to assume: an identity that Blake has appropriated but in which he has not yet come to feel at home, and whose otherness is marked by his allegorical status. Our earlier discussion of Coleridge is of relevance here, for Jerusalem, too, is a conversion narrative, and conversion offers us models for which we are not quite ready-hence the violence with which we must make ourselves imitate them.

The liminal structure of sublime allegory stops the poem from actually bringing Jerusalem into being, halting it in Golgonooza. As a gigantic construct whose body we cannot inhabit, as a voice without a face, a character like Los represents a series of functions and not an embodiment of Blake's redemptive vision. Through its disembodying use of allegory, then, the text performs a certain kind of activity that is not constatively related to any transcendental or visionary meaning that pre-

${ }^{10}$ Blake and Spenser (Baltimore: The Johns Hopkins University Press, 1985), p. 20.

${ }^{1}$ Personification and the Sublime: Milton to Coleridge (Cambridge, Mass.: Harvard University Press, 1985), pp. 2-3. 
cedes it nor predictively related to anything else that will happen in the 'real' world. Jerusalem is not, however, a ghost sonata, for it is hermeneutically grounded in 'Blake,' who models for us the existential necessity of wearing the mask of Los. As part of the process of miming the work of renovation, the text also produces metastatements such as the distinction of contraries from negations $\left(\mathrm{E}_{1} 5_{2-53} ; 10: 7-12\right.$. E162; $17: 33-36$ ). These credal passages should be seen as generated from within the text rather than as governing its interpretation. In other words, they are not dogmas that cause the poem to come into being in an illustrative capacity, but effects of the poem's need to organize itself as it is written. Not always consistent with each other in what they say, they are consistent at the level of their semiotic function. They tell us that textuality and narrativity must be organized, and that this task is accomplished through the invention of certitudes, bounding outlines, teleologies. The task is ongoing but also progressive, for Jerusalem consolidates the labor of Milton, whereas Urizen may well undo that of The Marriage. In this respect the later prophecies suggest a cultural praxis quite different from that of the earlier poems. If accorded a teleological privilege, the final poems represent themselves as advancing if not completing the stubborn structure. The early ones are constructed according to principles that require us to recompose and decompose that structure. 